\title{
Confamiliar transferability of simple sequence repeat (SSR) markers from cotton (Gossypium hirsutum L.) and jute (Corchorus olitorius L.) to twenty two Malvaceous species
}

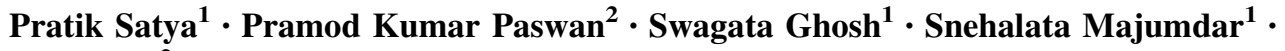 \\ Nasim $\mathrm{Ali}^{2}$
}

Received: 24 June 2015 / Accepted: 21 November 2015/Published online: 15 February 2016

(c) The Author(s) 2016. This article is published with open access at Springerlink.com

\begin{abstract}
Cross-species transferability is a quick and economic method to enrich SSR database, particularly for minor crops where little genomic information is available. However, transferability of SSR markers varies greatly between species, genera and families of plant species. We assessed confamiliar transferability of SSR markers from cotton (Gossypium hirsutum) and jute (Corchorus olitorius) to 22 species distributed in different taxonomic groups of Malvaceae. All the species selected were potential industrial crop species having little or no genomic resources or SSR database. Of the 14 cotton SSR loci tested, $13(92.86 \%)$ amplified in G. arboreum and $71.43 \%$ exhibited cross-genera transferability. Nine out of 11 jute SSRs $(81.81 \%)$ showed cross-transferability across genera. SSRs from both the species exhibited high polymorphism and resolving power in other species. The correlation between transferability of cotton and jute SSRs were highly significant $(r=0.813)$. The difference in transferability among species was also significant for both the marker groups. High transferability was observed at genus, tribe and subfamily level. At tribe level, transferability of jute SSRs (41.04\%) was higher than that of cotton SSRs (33.74\%). The tribe Byttnerieae exhibited highest SSR transferability $(48.7 \%)$. The high level of cross-genera transferability $(>50 \%)$ in ten species of Malvaceae, where no SSR resource is available, calls for
\end{abstract}

Pratik Satya

pscrijaf@gmail.com

1 Central Research Institute for Jute and Allied Fibres, Barrackpore, Kolkata 700120, India

2 Ramakrishna Mission Vivekananda University, Narendrapur, West Bengal, India large scale transferability testing from the enriched SSR databases of cotton and jute.

Keywords SSR - Confamiliar transferability - Cotton . Jute $\cdot$ Malvaceae $\cdot$ Taxonomic groups

\section{Introduction}

Microsatellites or simple sequence repeats (SSRs) are tandem repeats of short sequences (1-6 nucleotides) distributed throughout genomes, which can be identified through simple polymerase chain reaction (Morgante and Olivieri 1993). SSR markers are locus specific, multi-allelic, codominant and are highly polymorphic in plant and animal species (Wang et al. 2009). By virtue of their locus specificity and high polymorphism, SSRs are considered ideal DNA marker systems for evolutionary analysis, phylogeny reconstruction, genetic mapping and molecular breeding (Kalia et al. 2011). But the primary bottleneck of using SSRs in molecular research is the cost and effort required for designing of specific primers for amplification of locus specific SSRs, which involves sequencing of targeted genomic regions (Squirrell et al. 2003). This has limited the use of SSR markers primarily to species with enriched genomic resources. An alternate useful approach is to search for SSR markers transferable to closely related species or genera, which brings down the cost and time required for SSR development, particularly in species with limited or no genomic information (Peakall et al. 1998). Sequence data obtained from several crop species indicate sufficient homology between genomes in the regions harbouring microsatellites. Recently, comparative genomics in Brassica have shown that microsatellite characteristics in related species are highly similar (Shi et al. 2014). Thus, 
primer pairs designed on the basis of sequence of one species could be used to develop SSR markers for other related species. Such cross-amplification has been successfully utilized in many crops and their wild relatives for genetic differentiation and evolutionary studies (Sudheer et al. 2011; Tabbasam et al. 2014).

Cross-transferability of SSRs is often more successful between closely related species (Peakall et al. 1998; Balachandran et al. 2013). Limited information is available on confamiliar transferability of SSR markers in plants. Transfer rates of SSRs between genera is approximately $10 \%$ in Eudicots (Barbará et al. 2007), although high transferability between distant genera was observed in some cases (Gutierrez et al. 2005; Rai et al. 2013). But a systematic study to assess efficiency of transferability of SSR markers across different taxonomic orders in plants is limited.

The family Malvaceae harbours over 2300 diverse species belonging to 200 genera, of which only few species, cotton (Gossypium hirsutum L.), jute (Corchorus olitorius L.) and cocoa (Theobroma cacao) are industrially important crop species. Cotton is very rich in genomic resources, where more than 5000 SSR markers have been developed (Xiao et al. 2009). Similarly 2469 SSR markers have been developed in jute (Mir et al. 2009). But genomic resources are poor in other Malvaceous species. A good number of potential industrial crops and semi-domesticated species belong to Malvaceae, such as fibre crops like Hibiscus cannabinus (kenaf), Hibiscus acetosella (false roselle), $H$. vitifolius, Abutilon indicum (Indian mallow), Abroma augustum (Devil's cotton), Sida spp., Urena lobata; ornamental crops like $H$. rosa-sinensis (China rose), Alcea rosea (hollyhock), Malvaviscus arboreus (Turk's Cap), $H$. mutabilis (cotton rosemallow); and medicinally important species like Wissadula periplocifolia and Abelmoschus moschatus. Genomic resources are scanty in these species; thus cross-species transfer of SSRs from cotton and jute may be better option to develop SSR database in these Malvaceous species. A few recent reports indicate successful transferability of SSRs within same genus in Malvaceae (Bruna et al. 2009; Tabbasam et al. 2014), but these studies are limited to closely related species. We have earlier observed successful intergeneric amplification of genomic SSRs from jute in Hibiscus cannabinus and related wild species (Satya et al. 2013), which indicates the possibility of high SSR transferability in Malvaceae across genera. In the present study, we targeted amplification of SSR markers designed from cotton and jute in diverse Malvaceous genera to compare confamiliar transferability of SSR markers across different taxonomic levels, and also to investigate possibility of developing SSR resources in some minor crop species of Malvaceae through crosstransferability.

\section{Materials and methods}

\section{Plant materials and DNA isolation}

We studied cross species transferability of SSR markers from cotton $(G$. hirsutum) and jute (C. olitorius) in 22 Malvceous species belonging to 12 genera. Eight Hibiscus species (H. cannabinus, $H$. surattensis, $H$. acetosella, $H$. rosa-sinensis, $H$. schizopetalus, $H$. vitifolius, $H$. mutabilis and a synthetic $H$. cannabinus $x H$. surattensis allopolyploid) and one representative species each from Althea ( $A$. rosea), Abutilon (A. indicum), Abroma (A. augustum) and Urena (U. lobata) were obtained from Central Research Institute for Jute and Allied Fibres, Barrackpore, West Bengal, India $\left(22^{\circ} 45^{\prime} 35^{\prime \prime} \mathrm{N}\right.$ and $\left.88^{\circ} 25^{\prime} 36^{\prime \prime} \mathrm{E}\right)$. Three Sida species (S. cordifolia, S. acuta, S. rhombifolia), two Abelmoschus species (A. esculentum and A. moschatus) and one representative species each from Gossypium (G. arboretum), Malvaviscus (M. arboreus), Malvastrum (M. auratiacum), Pavonia (P. odorata) and Wissadula (W. periplocifolia) were collected from medicinal plant garden of Ramakrishna Mission Vivekananda University, Narendrapur, West Bengal $\left(22^{\circ} 26^{\prime} 18^{\prime \prime} \mathrm{N}\right.$ and $\left.88^{\circ} 24^{\prime} 1.4^{\prime \prime} \mathrm{E}\right)$. In addition, cross-genus transferability of cotton SSRs was also tested in $C$. olitorius. We did not test transferability of jute SSRs in cotton as cotton SSR database is already enriched. All the species were grown and identified through morphological characterization. Genomic DNA was extracted from leaf samples of single representative plant of each species by CTAB method (Doyle and Doyle 1990) with modifications (Satya et al. 2013). Leaf tissues were extracted in extraction buffer containing CTAB (2\%), Tris- $\mathrm{HCl}(100 \mathrm{mM}), \mathrm{NaCl}(1.4 \mathrm{M})$, EDTA $(20 \mathrm{mM})$ and $0.1 \mathrm{M} \beta$-mercaptoethanol, and incubated at $60{ }^{\circ} \mathrm{C}$ for $1 \mathrm{~h}$. One $\mathrm{ml}$ of extract was mixed gently with equal volume of dichloromethane and centrifuged at $14,000 \times g$ for $15 \mathrm{~min}$. The supernatant was mixed with isopropanol $(1 \mathrm{ml})$ and centrifuged at $14,000 \times g$ for $5 \mathrm{~min}$ to get the DNA pellet. The pellet was kept in $100 \%$ ethanol at $-20{ }^{\circ} \mathrm{C}$ for $24 \mathrm{~h}$, washed with $70 \%$ ethanol, air dried and stored in TrisEDTA $(10 \mathrm{mM})$ at $-20{ }^{\circ} \mathrm{C}$ for further analysis. The quality of the extracted DNA was checked by $\mathrm{A}_{260} / \mathrm{A}_{280}$ ratio using a spectrophotometer (Biospectrometer, Eppendorf, Germany).

\section{Microsatellite markers and PCR analysis}

A total of 14 SSRs specific to G. hirsutum (Xiao et al. 2009) and 11 SSRs specific to C. olitorius (Mir et al. 2009) were used to examine cross-genera transferability. The primers were synthesized from Metabion, Germany. The PCR reaction mixture $(20 \mu \mathrm{l})$ contained $20 \mathrm{ng}$ of template 
Table 1 SSR primers used for cross-amplification in Malvaceae

\begin{tabular}{|c|c|c|c|c|c|c|c|c|}
\hline \multirow{2}{*}{$\frac{\text { Species }}{\text { Cotton }}$} & \multirow{2}{*}{$\frac{\text { Primer }}{\text { C2-0004C }}$} & \multicolumn{2}{|c|}{ Primer sequence } & \multirow{2}{*}{$\frac{T_{\mathrm{m}}\left({ }^{\circ} \mathrm{C}\right)}{49.2}$} & \multirow{2}{*}{$\frac{\text { No. of alleles }}{2}$} & \multirow{2}{*}{$\begin{array}{l}\text { Allele size (bp) } \\
201\end{array}$} & \multirow{2}{*}{$\frac{\text { PIC }}{0.99^{\mathrm{a}}}$} & \multirow{2}{*}{$\frac{R_{\mathrm{p}}}{0.17}$} \\
\hline & & $\mathrm{F}$ & TTTGTTTTGCGTTCCTTTA & & & & & \\
\hline & & $\mathrm{R}$ & TCCGACAATGCCTTACAAG & & & & & \\
\hline & $\mathrm{C} 2-0005 \mathrm{~B}$ & $\mathrm{~F}$ & ССССАТТССТАСТСАТСС & 51.0 & 10 & 306 & 0.76 & 3.04 \\
\hline & & $\mathrm{R}$ & CACAGAAAGGTGCTCATGC & & & & & \\
\hline & CGR5501 & $\mathrm{F}$ & TCTCTCTTGCTGGTCACGAA & 53.1 & 6 & $145-166$ & 0.95 & 0.96 \\
\hline & & $\mathrm{R}$ & TGCCAAATACCCAAATCCAT & & & & & \\
\hline & CGR5503 & $\mathrm{F}$ & GCTGCTTCCATGCCATTATT & 57.5 & 3 & $111-127$ & 0.44 & 2.26 \\
\hline & & $\mathrm{R}$ & GGGTCGCTTTGTAAGTGAATG & & & & & \\
\hline & CGR5506 & $\mathrm{F}$ & CAGCAACCACAATTCGATCA & 57.5 & 5 & 156 & 0.66 & 2.43 \\
\hline & & $\mathrm{R}$ & GAAGTTGCTGTTGGGAAGGA & & & & & \\
\hline & CGR5508 & $\mathrm{F}$ & CAACTTTCCGAGCTGGATTC & 56.1 & 4 & 680 & 0.88 & 1.30 \\
\hline & & $\mathrm{R}$ & TGATCGAGGAATGAAAGCAA & & & & & \\
\hline & CGR5645 & $\mathrm{F}$ & GAGCGGAGAGTCCGGTTT & 54.5 & 2 & 134 & $0.99^{\mathrm{a}}$ & 0.17 \\
\hline & & $\mathrm{R}$ & CCCAAACGAATCAAAGATGG & & & & & \\
\hline & DC30003 & $\mathrm{F}$ & AGGAGGGAAAGAGTGGTG & 48.0 & 9 & 256 & 0.73 & 2.87 \\
\hline & & $\mathrm{R}$ & ССТССТСАСАТССААТСА & & & & & \\
\hline & DC30005 & $\mathrm{F}$ & ATGAGAAACGGTGTCGAA & 53.2 & 6 & 188 & 0.88 & 1.48 \\
\hline & & $\mathrm{R}$ & TTGACCGAATACTCCCCT & & & & & \\
\hline & DPL0840 & $\mathrm{F}$ & GAGTCGTTGCCGCTGTTTA & 55.2 & 5 & $152-182$ & 0.42 & 2.61 \\
\hline & & $\mathrm{R}$ & GCTACGACTCGATGTTACGG & & & & & \\
\hline & DPL 0848 & $\mathrm{~F}$ & AACCCAACCATCTTCACTGC & 55.0 & 6 & 255 & 0.99 & 0.52 \\
\hline & & $\mathrm{R}$ & TTGGTTTCCGATAGCCATAA & & & & & \\
\hline & SHIN0733 & $\mathrm{F}$ & GCTTTGCCTTCGGTTCATT & 56.5 & 3 & 208 & 0.95 & 0.26 \\
\hline & & $\mathrm{R}$ & GGACTTCGCTTTATGAATGCTT & & & & & \\
\hline & SHIN0745 & $\mathrm{F}$ & GCACCGAGTCTCCTATGCTC & 60.3 & 4 & 162 & 0.94 & 0.96 \\
\hline & & $\mathrm{R}$ & GGACCCTCAAACTTGTATTACACT & & & & & \\
\hline \multirow[t]{18}{*}{ Jute } & MJM 006 & $\mathrm{~F}$ & ACGTTTAGCAACTGATATTGG & 54.9 & 8 & 143 & 0.90 & 1.55 \\
\hline & & $\mathrm{R}$ & ACTTACAGCGGTTACATCATT & & & & & \\
\hline & MJM 211 & $\mathrm{~F}$ & ACGACAATCAATACGACAATC & 54.5 & 4 & 302 & 0.84 & 1.45 \\
\hline & & $\mathrm{R}$ & ATTCAGGCTTGATAACAGTGA & & & & & \\
\hline & MJM 472 & $\mathrm{~F}$ & CCATTCGTAGCATTAAAGTTTGC & 55.5 & 2 & 177 & 0.53 & 1.45 \\
\hline & & $\mathrm{R}$ & GATTGTGTGCAAACACGAGAG & & & & & \\
\hline & MJM 536 & $\mathrm{~F}$ & GTAGCCAAGTCTGCTTCCTGA & 56.0 & 2 & 316 & $0.99^{\mathrm{b}}$ & 0.09 \\
\hline & & $\mathrm{R}$ & TAGGTCACGAGAAGAGCGAAG & & & & & \\
\hline & MJM 563 & $\mathrm{~F}$ & CTTGGTTGTGGTGGTTGAACT & 55.5 & 5 & 318 & 0.87 & 1.36 \\
\hline & & $\mathrm{R}$ & AAACCCACCATAGTTGTGTGC & & & & & \\
\hline & MJM 609 & $\mathrm{~F}$ & TCAAATCCAAGCACCCATAAA & 54.2 & 8 & 334 & 0.76 & 2.55 \\
\hline & & $\mathrm{R}$ & AGAATTTGCGAAGTGGGCTAT & & & & & \\
\hline & MJM 618 & $\mathrm{~F}$ & CGTTATCAAGCAAATCCAACC & 54.5 & 8 & 305 & 0.79 & 2.36 \\
\hline & & $\mathrm{R}$ & CATCTGGTGACTGCTTCGTCT & & & & & \\
\hline & MJM 623 & $\mathrm{~F}$ & TTCTGCAGTTGTCTCCCTGTT & 60.0 & 8 & 319 & 0.66 & 2.36 \\
\hline & & $\mathrm{R}$ & ACGAGAAGACACAGTGGTGCT & & & & & \\
\hline & MJM 634 & $\mathrm{~F}$ & GGAGAATATAAGGCCGCGTAG & 62.2 & 3 & 110 & 0.83 & 1.00 \\
\hline & & $\mathrm{R}$ & CAGCGGTGTAAGGCTCTCTC & & & & & \\
\hline
\end{tabular}

$T_{\mathrm{m}}$ Melting temperature, PIC polymorphism information content, $R \mathrm{p}$ resolving power

a Amplified only in G. arboreum

b Amplified only in H. rosa-sinensis 
DNA, $0.4 \mu \mathrm{l}$ of dNTPs $(0.2 \mathrm{mM})$ (Invitrogen, USA), $2 \mu \mathrm{l}$ of $50 \mathrm{mM} \mathrm{MgCl} 2,0.4 \mu \mathrm{l}$ of each primer $(10 \mu \mathrm{M}), 1 \mathrm{U}$ of Taq DNA polymerase (Invitrogen, USA) and $2 \mu \mathrm{l}$ of $1 \times$ PCR buffer. The samples were amplified in a thermal cycler (Mastercycler Nexus Gradient, Eppendorf, Germany) with an initial denaturation at $94{ }^{\circ} \mathrm{C}$ for $5 \mathrm{~min} ; 30$ cycles of denaturation at $94{ }^{\circ} \mathrm{C}$ for $1 \mathrm{~min}$, primer annealing at specific annealing temperature for $1 \mathrm{~min}$ and primer extension at $72{ }^{\circ} \mathrm{C}$ for $1 \mathrm{~min}$; final extension at $72{ }^{\circ} \mathrm{C}$ for $8 \mathrm{~min}$. The annealing temperature was initially determined as $2{ }^{\circ} \mathrm{C}$ lower than melting temperature $\left(T_{\mathrm{m}}\right)$ and varied for obtaining optimal annealing temperature for obtaining reproducible amplification (Table 1). PCR products were separated using $6 \%$ polyacrylamide gel electrophoresis using 100 bp DNA ladder (Invitrogen, USA) as standard. Amplification patterns were photographed in a gel documentation system (Bio-Rad, USA).

\section{Data analysis}

Each analysis was replicated five times and signals were considered positive if $80 \%$ of the samples exhibited PCR amplification. Based on signal intensity, the amplicons were classified in four classes following Kuleung et al. (2004) and Rai et al. (2013). Amplicons having moderate to strong signals were considered for further analysis. Cross-genera transferability of each SSR was determined by the percentage of genera amplifying the marker. Crossgenera transferability of all the SSR markers in a genus was calculated as the percentage of amplified SSRs in that genus. Significance of the difference in transferability of SSRs was tested by Student's $t$ test. We also estimated the correlation between transferability of jute and cotton SSRs and tested the significance of the correlation by $t$ test. The polymorphic information content (PIC) of each SSR marker was calculated using the formula: PIC $=1-\sum\left(p_{i}\right)^{2}$ where $p_{i}$ is the frequency of the $i$ th allele. Marker resolving power was determined from band informativeness $\left(I_{\mathrm{b}}\right)$ as suggested by Anderson et al. (1993).

\section{Results and discussion}

The present study is the first report on confamiliar transferability of SSR markers in Malvaceae. The study was carried out to determine the transferability of jute and cotton microsatellites to 22 Malvaceous genera. Out of 14 cotton SSRs 13 markers produced a total of 66 alleles in 23 species (including $C$. olitorius) with a size range of 112-923 bp (Average 336 bp). Four SSR markers, C2005B, DC300003, DPL0840 and CGR5503 exhibited more than $50 \%$ transferability in these species. The number of alleles amplified by cotton SSRs ranged from 2 to 10 with an average of 5.08 alleles per marker (Table 1). The PIC values for the SSR markers varied from 0.42 for DPL0840 to 0.99 for DPL0848, with an average of 0.78. Marker C20005B exhibited highest resolving power (3.04), while resolving power per allele was highest for CGR5503 (0.75) (Table 1).

Significant differences among species was observed for cotton SSR transferability $\left(t_{19}=5.84, P<0.001\right)$. Of the $14 G$. hirsutum SSR markers 13 were amplified in sister taxa G. arboreum (92.86\% transferability) producing a total of 35 alleles. Since the tetraploid $G$. hirsutum genome $(A A B B)$ originated from diploid $A A$ genome of $G$. arboreum, high SSR transferability is expected between these two species. Three SSRs C2-004C, CGR5645 and SHIN0733 failed to amplify in other genera. Among the 12 genera, transferability was highest in Abutilon (57.14\%) and Malvaviscus (57.14 \%). No SSR was amplified in Malvastrum and Urena. Transferability of cotton SSRs was higher in Corchorus (50.0\%) than in Hibiscus $(40.18 \%)$.
Table 2 Transferability of SSR markers across tribes and subfamilies in Malvaceae

\begin{tabular}{lll}
\hline From & To & Transferability (\%) \\
\hline Sparmanniaceae & Hibisceae & 32.97 \\
& Byttnerieae & 54.55 \\
& Malveae & 22.08 \\
Gossypieae & Gossypieae & 54.55 \\
& Hibisceae & 40.00 \\
Grewoideae & Byttnerieae & 42.86 \\
& Malveae & 18.37 \\
Malvoideae & Malvoideae & 38.09 \\
& Byttnerioideae & 54.55 \\
& Byttnerioideae & 42.86 \\
\hline
\end{tabular}


Fig. 1 Comparative confamiliar transferability of jute and cotton SSR markers

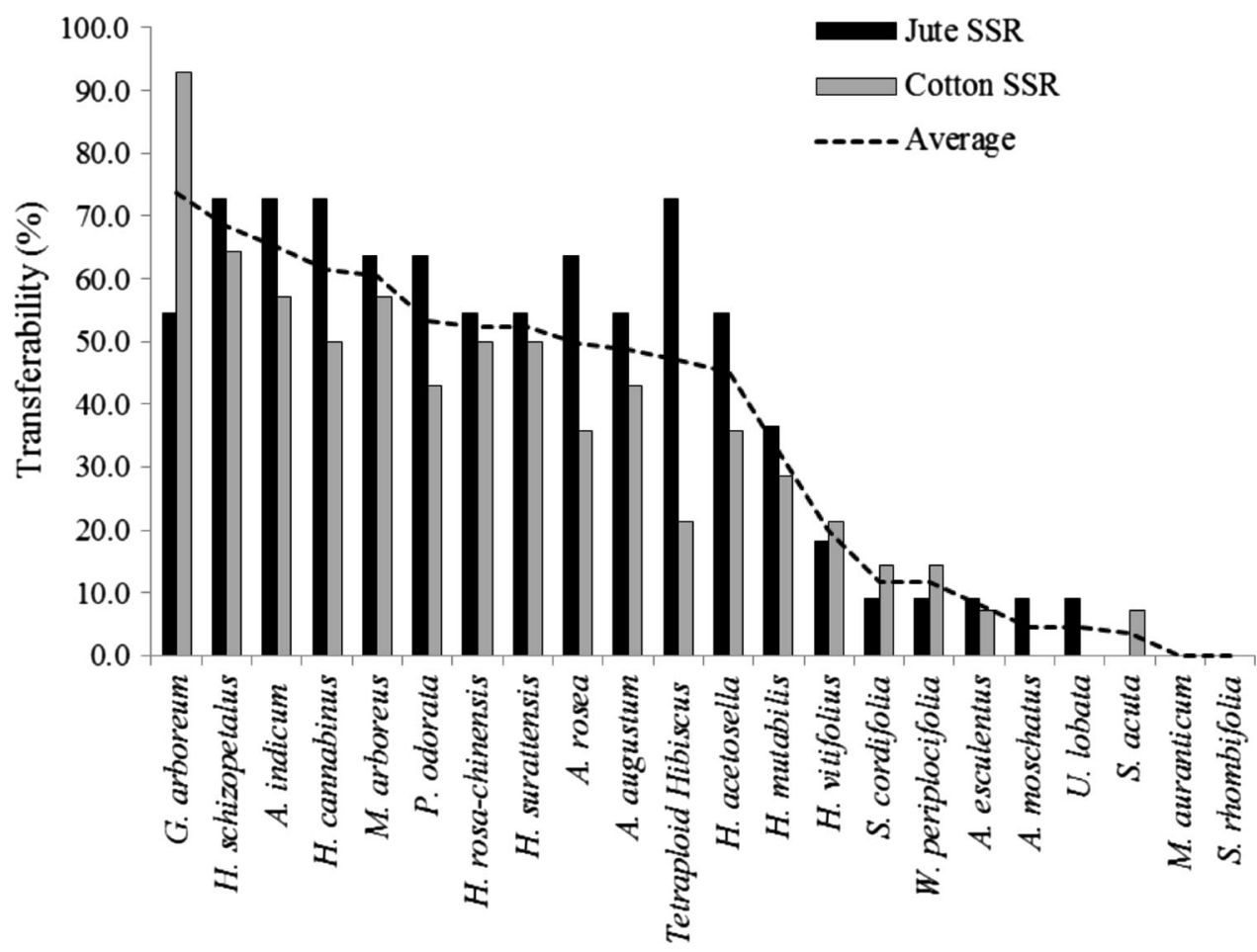

At the species level, highest transferability was exhibited by $H$. schizopetalus (64.29\%). The species S. rhombifolia, A. moschatus, M. auranticum and $U$. lobata did not show any reproducible amplification.

Nine SSR markers from jute exhibited successful crossgenera amplification, whereas two SSRs failed to amplify in other Malvaceous species. A total of 48 alleles were amplified by these SSRs with an average of 5.3 alleles per marker (Table 1). The allele size ranged from 104 to $759 \mathrm{bp}$ with an average of $331 \mathrm{bp}$. Average PIC value for jute SSRs was 0.80 (range 0.53-0.99). Highest $R_{\mathrm{p}}$ was exhibited by MJM 618 and MJM 623 (2.36).

The resolving power of a marker is an indication of the utility of the markers in assessing genetic differentiation and diversity. A resolving power of greater than one is considered more informative (Azevedo et al. 2012). Out of 23 markers used in the study, 15 markers exhibited a $R_{\mathrm{p}}$ value of $\geq 1.0$ (Table 1 ). The average $R_{\mathrm{p}}$ of cotton (1.46) and jute (1.58) SSRs indicated that both groups of SSRs are useful for genetic discrimination and diversity studies, though more number of jute SSRs (88.9\%) exhibited resolving power of $\geq 1.0$ compared to cotton SSRs (40\%). The resolving powers of the cotton and jute SSRs observed in Malvaceae are similar to our earlier findings in Hibiscus (Satya et al. 2013) and also to other cross-transferability studies, such as Vigna angularis SSRs in Vigna radiata (Singh et al. 2014) and pearl millet SSRs in Pennisetum purpureum (Azevedo et al. 2012).
Average cross-genera transferability of Jute SSRs was higher $(38.84 \%)$ than that of cotton SSRs $(32.30 \%$; Fig. 1). Cross-genera transferability was highest in $\mathrm{Abu}$ tilon (72.73\%) followed by Malvaviscus and Pavonia (63.64\%). The jute SSRs showed lower transferability to Gossypium (54.55\%) than cotton SSRs. The SSRs failed to amplify in S. rhombifolia, S. acuta and M. aurantiacum. At the species level, significant difference was observed for SSR cross-amplification $\left(t_{19}=6.40, P<0.0001\right)$. Highest transferability was observed in $H$. cannabinus, $H$. schizopetalus and A. indicum $(72.73 \%)$. We found a significant positive correlation between the cross-species transferability of cotton and jute SSR markers ( $r=0.813$, $P<0.0001)$, which indicate a similar pattern of transferability of these two groups of SSRs in Malvaceae.

Peakall et al. (1998) suggested that cross-transferability of SSRs within a genus can vary from 50 to $100 \%$, while transferability across genera is usually below $50 \%$. In the present study, more than $50 \%$ transferability was observed in ten Malvaceous species from different taxonomic groups (Fig. 1). The findings are in accordance with earlier reports on cross-genera transferability, for instance from mulberry to fig and jackfruit (45.74-71.80\%; Balachandran et al. 2013), Psidium guajava to other Myrtaceae species (60.8-78.2\%; Rai et al. 2013), tall fescue to several grasses (47.8-66.2\%; Saha et al. 2006), C. olitorius to Hibiscus spp. (48 \%; Satya et al. 2013) and Litchi chinensis to Blighia sapida (58\%) (Ekue et al. 2009). 
The thirteen genera in which intergeneric transferability was tested belonged to five tribes, Byttnerieae (Abroma), Gossypieae (Gossypium), Hibisceae (Abelmoschus, Hibiscus, Malvaviscus, Pavonia, Urena), Malveae (Abutilon, Alcea, Malvastrum, Sida, Wissadula) and Sparmanniaceae (Corchorus) (Stevens 2001). Of these, cross-transferability was successful from Gossypieae and Sparmanniaceae to all the other tribes, establishing high confamiliar transferability of SSRs within Malvaceae. The tribe Byttnerieae exhibited higher cross transferability (48.7\%) than other two tribes Hibisceae (39.21\%) and Malveae (20.22 \%). At higher taxonomic level, transferability was also successful from subfamily Grewoideae (containing $C$. olitorius) to other subfamilies Malvoideae (38.09\%) and Byttnerioideae $(54.54 \%)$ and also from Malvoideae (containing $G$. hirsutum) to Grewoideae (50.0\%) and Byttnerioideae (42.86 \%; Table 2). The extent of transferability, however, did not match well with subfamily classification, since cotton SSRs did not amplify well in Abelmoschus, Malvastrum, Sida and Urena, all of which belong to same subfamily (Malvoideae) as cotton. Under Malvoideae cotton belongs to a different tribe Gossypieae, while Abelmoschus and Urena belong to Hibisceae and Malvastrum and Sida belong to Malveae. The other members of Hibsiceae excluding genus Abelmoschus exhibited good cross transferability from cotton $(42.14 \%)$ and jute $(56.36 \%)$, indicating cross-tribe transferability may not be low from Gossypieae and Sparmanniaceae to Hibisceae. The two Abelmoschus species included in the study, A. esculentus $(2 n=108-144)$ and $A$. moschatus $(2 n=72)$ bear large genome distributed over many chromosomes (Hamon and van Sloten 1995). A. esculentus is an allopolyploid with variable level of ploidy. These factors might have limited intergeneric transferability of SSRs in Abelmoschus, but considerable inter-tribe transferability can be realized in Hibisceae.

Given the high number of SSRs discovered in cotton and jute, confamiliar transferability is more rapid and economic option to develop a robust SSR database in these species. Confamiliar transferability of SSR markers from cotton and jute will benefit molecular genetic studies, species conservation, ecological studies and genetic improvement. The present study did not find good prospects for transferability of SSR markers in Abelmoschus, Malvastrum, Sida or Urena from cotton and jute. Although more SSRs need to be screened for comprehensive result, the trend of amplification of SSR markers from two different species indicates transferability of SSR markers may be less successful in these species. Development of SSRs from mining sequence information would be more appropriate for Abelmoschus, Malvastrum, Sida and Urena.

The present analysis stands to support that genomic SSRs are transferable across genera, tribes and subfamilies within Malvaceae. The report can serve as a guideline for adopting different approaches of SSR marker development in these species/genera, either by cross-amplification or by sequence mining. As most of the Malvaceous species do not have genomic or EST sequence information, we suggest that $50 \%$ transferability may be optimal for targeting cross-genera amplification. Considering high number of SSR markers in cotton and jute, a transferability of $30 \%$ may also be acceptable to build an initial SSR pool for genomic researches in species where sequence based SSR development may be problematic due to polyploidy or large genome size.

Acknowledgments The authors acknowledge Vice-Chancellor, Ramakrishna Mission Vivekananda University and Director, Central Research Institute for Jute and Allied Fibres for the support provided in carrying out the research work and also thank the two anonymous reviewers for their positive comments and suggestions to improve the manuscript.

\section{Compliance with ethical standards}

Conflict of interest The authors declare no conflict of interest in the publication.

Open Access This article is distributed under the terms of the Creative Commons Attribution 4.0 International License (http:// creativecommons.org/licenses/by/4.0/), which permits unrestricted use, distribution, and reproduction in any medium, provided you give appropriate credit to the original author(s) and the source, provide a link to the Creative Commons license, and indicate if changes were made.

\section{References}

Anderson JA, Churchill GA, Autrique JE, Tanksley SD, Sorrells ME (1993) Optimizing parental selection for genetic-linkage maps. Genome 36:181-186

Azevedo ALS, Costa PP, Machado JC, Machado MA, Pereira AV, da Silva Lédo FJ (2012) Cross species amplification of Pennisetum glaucum microsatellite markers in Pennisetum purpureum and genetic diversity of napier grass accessions. Crop Sci 52:1776-1785

Balachandran M, Kadam NN, Biradar J, Reddy SH, Ankaiah M, Narayanan MJ, Udayakumar M, Khurana P, Sreeman SM (2013) Development and characterization of microsatellite markers for Morus spp. and assessment of their transferability to other closely related species. BMC Plant Biol 13:194

Barbará T, Palma-Silva C, Paggi GM, Bered F, Fay MF, Lexer C (2007) Cross-species transfer of nuclear microsatellite markers: potential and limitations. Mol Ecol 16:3759-3767

Bruna S, Portis E, Braglia L, De Benedetti L, Comino C, Acquadro A, Mercuri A (2009) Isolation and characterization of microsatellite markers from Hibiscus rosa-sinensis (Malvaceae) and crossspecies amplifications. Conserv Genet 10:771-774

Doyle JJ, Doyle JL (1990) Isolation of plant DNA from fresh tissue. Focus 12:13-15

Ekue MRM, Gailing O, Finkeldey R (2009) Transferability of simple sequence repeat (SSR) markers developed in Litchi chinensis to Blighia sapida (Sapindaceae). Plant Mol Biol Rep 27:570-574 
Gutierrez MV, Vaz Patto MC, Huguet T, Cubero JI, Moreno MT, Torres AM (2005) Cross-species amplification of Medicago truncatula microsatellites across three major pulse crops. Theor Appl Genet 110:1210-1217

Hamon S, van Sloten DH (1995) Okra Abelmoschus esculentus, A. caillei, A. manihot, A. moschatus (Malvaceae). In: Smartt J, Simmonds NW (eds) Evolution of crop plants, 2nd edn. Longman Scientific \& Technical, Harlow, pp 350-357

Kalia RK, Rai MK, Kalia S, Singh R, Dhawan AK (2011) Microsatellite markers: an overview of the recent progress in plants. Euphytica 177:309-334

Kuleung C, Baenziger PS, Dweikat I (2004) Transferability of SSR markers among wheat, rye, and triticale. Theor Appl Genet 108:1147-1150

Mir RR, Banerjee S, Das M, Gupta V, Tyagi AK, Sinha MK, Balyan HS, Gupta PK (2009) Development and characterization of large-scale simple sequence repeats in jute. Crop Sci 49:1687-1694

Morgante M, Olivieri AM (1993) PCR-amplified microsatellites as markers in plant genetics. Plant J 3:175-182

Peakall R, Gilmore S, Keys W, Morgante M, Rafalski A (1998) Cross-species amplification of soybean (Glycine max) simple sequence repeats (microsatellites) within the genus and other legume genera-implications for the transferability of microsatellites in plants. Mol Biol Evol 15:1275-1287

Rai MK, Phulwaria M, Shekhawat NS (2013) Transferability of simple sequence repeat (SSR) markers developed in guava (Psidium guajava L.) to four Myrtaceae species. Mol Biol Rep 40:5067-5071

Saha MC, Cooper JD, Mian MAR, Chekhovskiy K, May GD (2006) Tall fescue genomic SSR markers: development and transferability across multiple grass species. Theor Appl Genet 113:1449-1458
Satya P, Karan M, Kar CS, Mahapatra AK, Mahapatra BS (2013) Assessment of molecular diversity and evolutionary relationship of kenaf (Hibiscus cannabinus L.), roselle (H. sabdariffa L.) and their wild relatives. Plant Syst Evol 299:619-629

Shi J, Huang S, Zhan J, Yu J, Wang X, Hua W, Liu S, Liu G, Wang H (2014) Genome-wide microsatellite characterization and marker development in the sequenced Brassica crop species. DNA Res 21:53-68

Singh A, Dikshit HK, Jain N, Singh D, Yadav RN (2014) Efficiency of SSR, ISSR and RAPD markers in molecular characterization of mungbean and other Vigna species. Indian J Biotechnol $13: 81-88$

Squirrell J, Hollingsworth PM, Woodhead M, Russell J, Lowe AJ, Gibby M, Powell W (2003) How much effort is required to isolate nuclear microsatellites from plants? Mol Ecol 12:1339-1348

Stevens PF (2001) onwards. Angiosperm Phylogeny Website. Version 12 July 2012. http://www.mobot.org/MOBOT/research/APweb/. Accessed on 22 Sept 2014

Sudheer PDVN, Mastan SG, Rahman H, Prakash CR, Singh S, Reddy MP (2011) Cross species amplification ability of novel microsatellites isolated from Jatropha curcas and genetic relationship with sister taxa. Mol Biol Rep 38:1383-1388

Tabbasam N, Zafar Y, Rahman M (2014) Pros and cons of using genomic SSRs and EST-SSRs for resolving phylogeny of the genus Gossypium. Plant Syst Evol 300:559-575

Wang ML, Barkley NA, Jenkins TM (2009) Microsatellite markers in plants and insects. Part I. Applications of biotechnology. Genes Genomes Genom 3:54-67

Xiao J, Wu K, Fang DD, Stelly DM, Yu J, Cantrell RG (2009) New SSR markers for use in cotton (Gossypium spp.) improvement. J Cotton Sci 13:75-157 